\title{
Synthesis and immobilization of silver nanoparticles on aluminosilicate nanotubes and their antibacterial properties
}

\author{
G. Ipek Yucelen ${ }^{1} \cdot$ Rachel E. Connell ${ }^{2} \cdot$ Jessica R. Terbush $^{1} \cdot$ David J. Westenberg $^{2}$ • \\ Fatih Dogan ${ }^{1}$
}

Received: 7 May 2015/Accepted: 30 May 2015/Published online: 17 June 2015

(c) The Author(s) 2015. This article is published with open access at Springerlink.com

\begin{abstract}
A novel colloidal method is presented to synthesize silver nanoparticles on aluminosilicate nanotubes. The technique involves decomposition of $\mathrm{AgNO}_{3}$ solution to Ag nanoparticles in the presence of aluminosilicate nanotubes at room temperature without utilizing of reducing agents or any organic additives. Aluminosilicate nanotubes are shown to be capable of providing a unique chemical environment, not only for in situ conversion of $\mathrm{Ag}^{+}$into $\mathrm{Ag}^{0}$, but also for stabilization and immobilization of $\mathrm{Ag}$ nanoparticles. The synthesis strategy described here could be implemented to obtain self-assembled nanoparticles on other single-walled metal oxide nanotubes for unique applications. Finally, we demonstrated that nanotube/nanoparticle hybrid show strong antibacterial activity toward Gram-positive Staphylococcus epidermidis and Gram-negative Escherichia coli.
\end{abstract}

Keywords Nanotube $\cdot$ Metal oxide $\cdot$ Metal .

Nanoparticle $\cdot$ Antibacterial

\section{Introduction}

New multifunctional nanoparticle-nanotube hybrid systems, due to their unique and superior properties compared with their pure counterparts, increasingly forming the foundation of transformational developments in areas as

G. Ipek Yucelen

yuceleng@mst.edu

1 Materials Research Center, Missouri University of Science and Technology, Rolla, MO 65409, USA

2 Department of Biological Sciences, Missouri University Science and Technology, Rolla, MO 65409, USA diverse as electronics, photonics, catalysis, biotechnology, and energy storage among many other applications ( $\mathrm{Wu}$ et al. 2011; Mackiewicz et al. 2008; Georgakilas et al. 2007; Kong et al. 2007; Li et al. 2009). Single-walled aluminosilicate nanotubes (AlSiNTs) are excellent candidates for fabricating various functional nanohybrid materials due to their well-defined one-dimensional structure (Yucelen et al. 2011; Thill et al. 2012), vast range of tunable compositions (Avellan et al. 2014), functionalizable surfaces (Kang et al. 2011), attainability in pure form without a catalyst (Yucelen et al. 2011), and ability to readily form hydrogels, transparent films, powders, and coatings (Jiravanichanun et al. 2011; Kang et al. 2012; Kuroda et al. 2012). As shown in Fig. 1a, b, AlSiNTs have ordered wall structure that is identical to a layer of aluminum (III) hydroxide (gibbsite) with tetrahedral silanol $(\equiv \mathrm{Si}-\mathrm{OH})$ groups attached at the inner side. Outer diameter of AlSiNTs is around $2.2 \mathrm{~nm}$, while their average length is about $100 \mathrm{~nm}$. AlSiNTs form colloidal three-dimensional (3D) networks of hexagonally packed bundles due to entanglement and hydrogen bonding among the nanotubes (Fig. 1c). One can easily obtain a variety of AlSiNT structures (Thill et al. 2012; Avellan et al. 2014; Kang et al. 2011), or achieve precise control over dimensional and morphological parameters by replacing the $\mathrm{Si}$ source (Boyer et al. 2014; Levard et al. 2010) and use different acids (Yucelen et al. 2012) during their aqueous phase synthesis, which presents new possibilities for a number of applications involving, but not limited to, molecular transport (Kang et al. 2011), bio-molecular sensing (Jiravanichanun et al. 2011), molecular separation (Kang 2012), and bone tissue engineering (Ishikawa et al. 2010).

Yet another important class of materials, noble metal particles (NMPs), especially silver nanoparticles (AgNPs), 

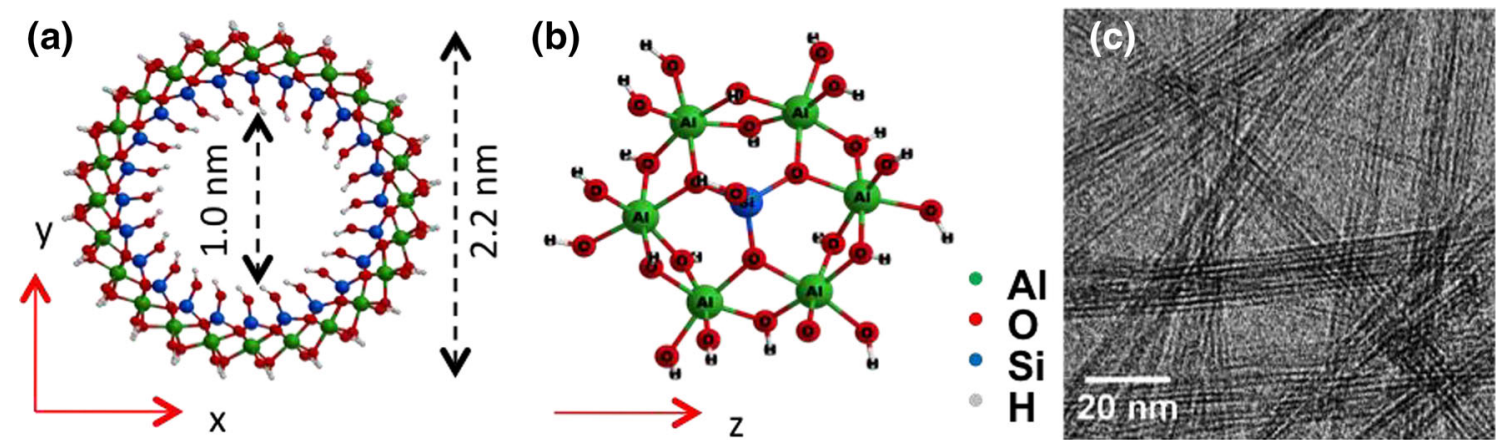

Fig. 1 a View down the axis of an AlSiNT. b View of hexagonal building unit along the radius of the nanotube wall that is composed of silicon tetrahedron joint to 6 aluminum octahedron via three oxygen bridges. c Cryo-electron microscopy image of AlSiNT network (Kang et al. 2010)

has been extensively investigated for catalysis, textile industry, water disinfection, cosmetics, and food packaging owing to their unique physical and chemical properties (Lee and El-Sayed 2006; Rai et al. 2009; Jiang et al. 2005). However, it is a challenge to synthesize MNPs with high dispersion and small particle size because particles suffer from the drawback of agglomeration, which causes undesirable changes to their properties and restricts their applications (Moritz and Geszke-Moritz 2013). There are many traditional synthetic routes to formation of MNPs including chemical treatment (Sun and Xia 2002; Kumar 2007; Sondi et al. 2003), irradiation (Henglein and Giersig 1999; Yin et al. 2004; Abid et al. 2002; Pol et al. 2005), thermal treatment (Navaladian et al. 2007), and photochemical (Huang et al. 1996), or radiolytic reduction (Krklješ et al. 2007). Many of these methods are time consuming and require the usage of additional chemicals such as sodium borohydride $\left(\mathrm{NaBH}_{4}\right)$ as reducing agent and polyvinyl pyrrolidine (PVP) as stabilizer or protecting agent, which can affect the surface properties of nanoparticles and diminish the overall performance of the material. Prevention of the impurities resulting from the usage of additional chemicals, minimizing the time and preparation costs, achieving large-scale synthesis with good reproducibility and controllable nanoparticle characteristics remains challenging.
To this end, we apply a fast, facile, and generalizable new synthesis strategy to construct novel nanohybrid architectures comprised of AgNPs and AlSiNTs, without using of reducing/stabilizing agents, or irradiation, by onestep facile and convenient colloidal approach, in which AlSiNTs act as unique templates and carriers to AgNPs. While pristine AlSiNTs and AgNPs are known to have remarkable properties, their hybrids not only present a new field of basic research, but also endow new and enhanced functions with performances far beyond those of the individual counterpart materials, which will lead to the creation of novel nanohybrid systems for practical applications with significantly improved performance. In this paper, we show the potential of AlSiNT/AgNP nanocomposites as an antibacterial agent, and this finding may be useful in the application of single-walled metal oxide nanotube-based hybrids against clinically important Gram-negative and Gram-positive bacteria.

\section{Experimental details}

A facile, convenient, generalizable, and scalable aqueous phase-based strategy has been developed for the preparation of AlSiNT/AgNP hybrids at room temperature. It involves hydrothermal synthesis of AlSiNTs followed by
Fig. 2 Schematic illustration for the fabrication of AlSiNT/ AgNP nanohybrids is shown with a digital image of the asobtained colloidal nanohybrid dispersion

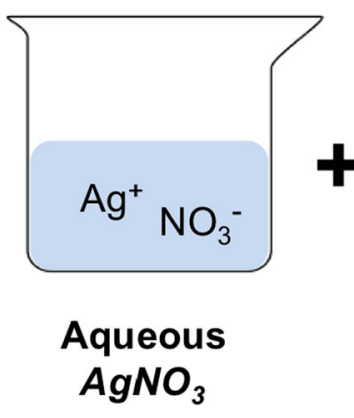

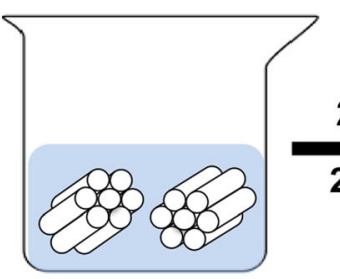

AISiNT Dispersion
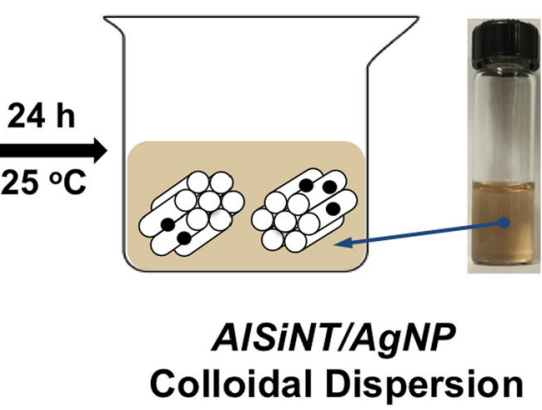
in situ generation of AgNPs from silver nitrate $\left(\mathrm{AgNO}_{3}\right)$ solution in the presence of AlSiNTs, without using of an additional chemical or treatment. All chemicals were purchased from Sigma-Aldrich and used as received without further purification.

\section{Aluminosilicate nanotube synthesis}

To synthesize AlSiNTs, $0.05 \mathrm{M}$ TEOS (tetraethoxysilane) was mixed with $0.1 \mathrm{M}$ ASB (aluminum tri-secbutoxide), and the mixture was introduced dropwise to a mildly acidic solution of $0.05 \mathrm{M} \mathrm{HCl}$. The obtained solution was kept under vigorous stirring for $24 \mathrm{~h}$ at $25{ }^{\circ} \mathrm{C}$. The solution was then diluted to $0.02 \mathrm{M} \mathrm{Al}$ and the temperature was increased to $95{ }^{\circ} \mathrm{C}$. The reaction lasted for 4 days $(96 \mathrm{~h})$. At the end of the reaction, the nanotubes were precipitated by dropwise addition of a 30 wt $\%$ ammonia solution. The resulting gel was centrifuged, and the supernatant was discarded. Then, $10 \mathrm{~N}$ $\mathrm{HCl}$ was added dropwise to redisperse the nanotubes. Finally, the dispersion was dialyzed for 4 days against deionized water using a $15-\mathrm{kDa}$ membrane. Pure nanotube networks are obtained by freeze-drying of the precipitates for $24 \mathrm{~h}$.

\section{Preparation of AlSiNT/AgNP nanohybrids}

Typically, $0.02 \mathrm{~g}$ AlSiNTs were added to $10 \mathrm{ml}$ of deionized water and stirred for $10 \mathrm{~min}$ at ambient temperature. In a separate flask, $0.01 \mathrm{~g} \mathrm{AgNO}_{3}$ was dissolved in $10 \mathrm{ml}$ of deionized water. While stirring at room temperature, nanotube dispersion was then added dropwise to $\mathrm{AgNO}_{3}$ solution. The solution with nanotubes was stirred for $2 \mathrm{~h}$, which is a crucial step in the formation of AgNPs. The mixture was placed in a vial and kept at room temperature for $24 \mathrm{~h}$. The colloidal dispersion of AlSiNT/AgNP nanohybrids is separated from the solution by centrifugation at $7000 \mathrm{rpm}$ for $10 \mathrm{~min}$. The resulting colloidal dispersion has very light tallow color (Fig. 2).

\section{Characterization methods}

Electron microscope images were taken on a Tecnai F20 transmission electron microscope (TEM) with an
Fig. 3 a, b TEM images of AlSiNT/AgNP hybrids. c Particle size distribution calculated using Image J software based on TEM images. d EDX spectrum of pure AlSiNTs. e EDX spectrum of AlSiNTs decorated with AgNPs. Copper $(\mathrm{Cu})$ signal is due to TEM grid
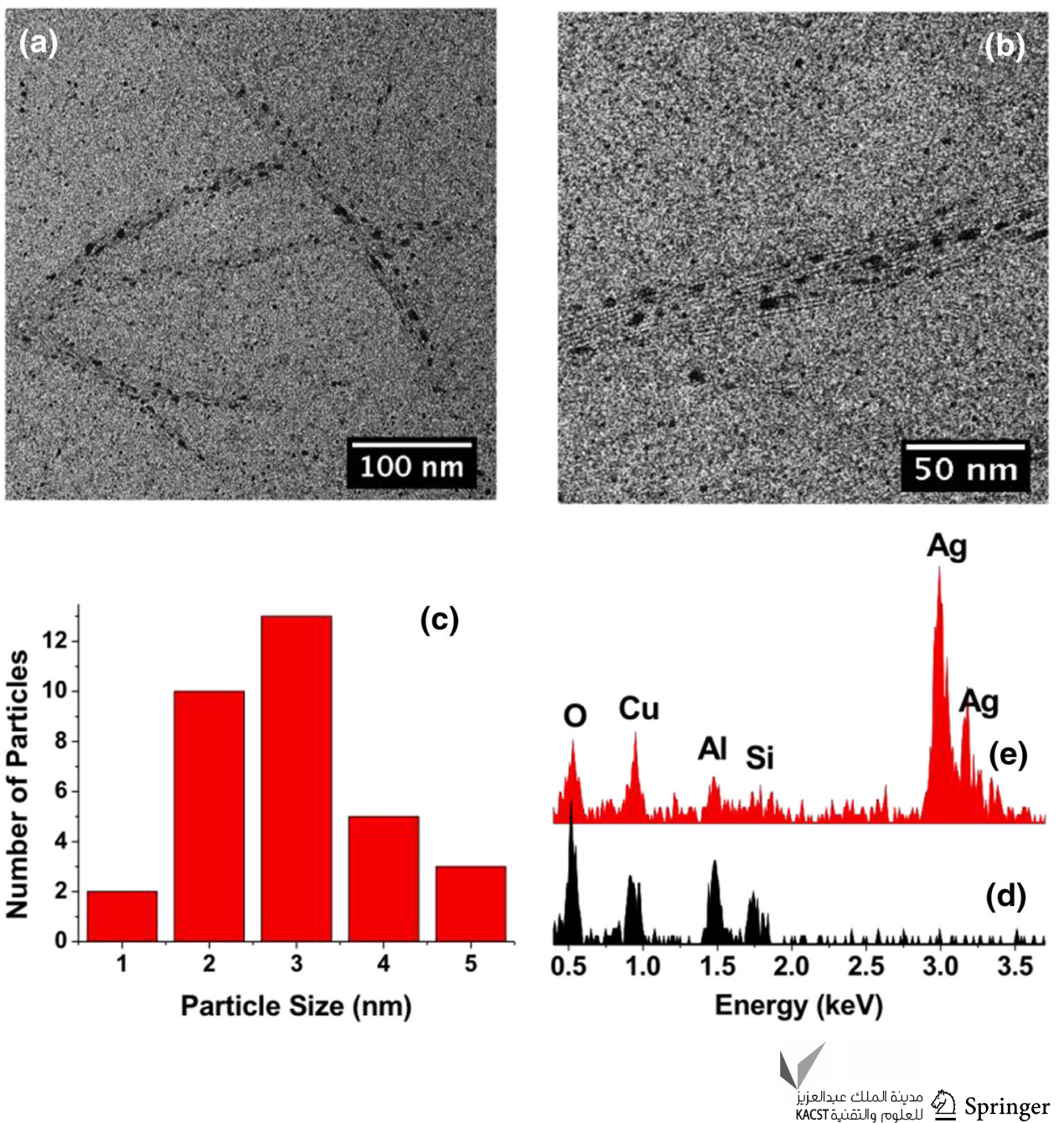
Fig. 4 Dark-field STEM images of AlSiNT/AgNP nanohybrids at different magnifications
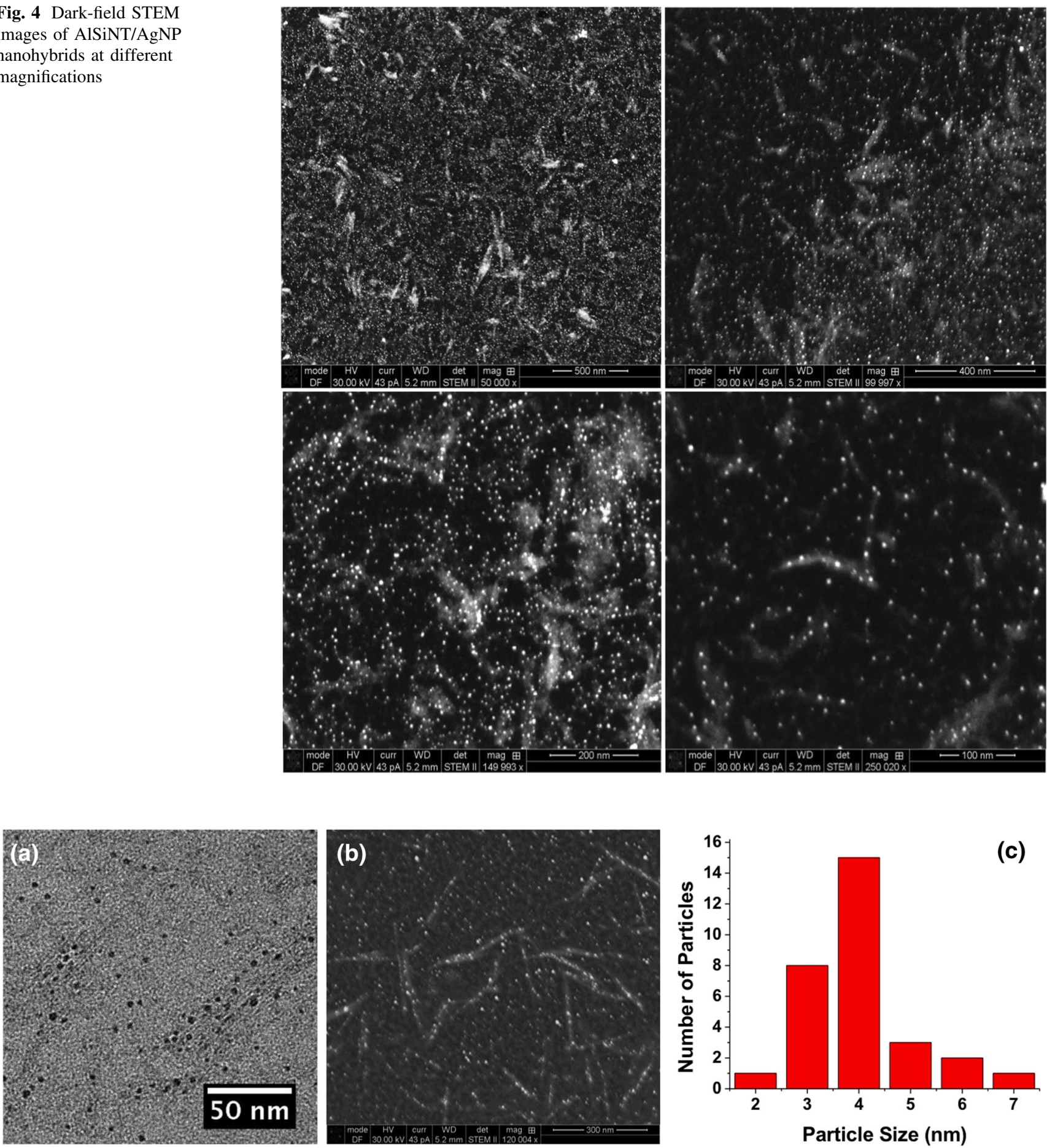

Fig. 5 a TEM image and b dark-field STEM image of colloidal dispersion of AlSiNT/AgNP nanohybrids obtain 60 days after initial preparation. c Particle size distribution calculated using ImageJ software based on TEM images

operating voltage of $200 \mathrm{kV}$. Dark-field scanning transmission electron microscopy (STEM) images were obtained by Helios Nanolab 600 FIB at $30 \mathrm{kV}$. The samples were prepared using ultrathin carbon TEM grids
(Ted Pella) by dropping a small amount of the AlSiNT/ AgNP nanohybrid dispersion on the grid, removing the extra solution using a blotting paper and allowing the TEM grid to dry. 


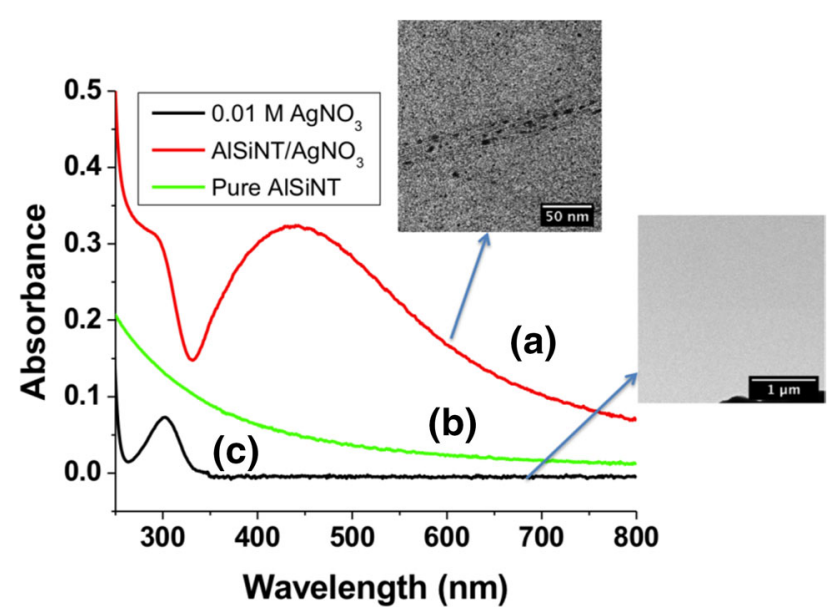

Fig. 6 a UV-Vis spectra of AlSiNT/AgNP nanohybrid colloidal solutions with the corresponding TEM image. b UV-Vis spectra of pure AlSiNTs dispersed in $\mathrm{H}_{2} \mathrm{O}$. c UV-Vis spectra of dissolved $0.01 \mathrm{M} \mathrm{AgNO}_{3}$ in $\mathrm{H}_{2} \mathrm{O}$ and corresponding TEM image

\section{Assessing antibacterial activity}

The Gram-positive S. epidermidis (ATCC 35984) and Gram-negative E. coli (ATCC 25922) were chosen as test organisms. Both organisms were grown in Trypticase Soy broth at 37 degrees C. Overnight cultures of each organism were diluted to approximately 1000 colony forming units (cfu) per $0.1 \mathrm{~mL} .1 \mathrm{~mL}$ of the diluted culture was combined with $100 \mu \mathrm{l}$ of the solution that was tested. Antibacterial activities of three samples were tested against each type of bacteria. Samples tested were $0.01 \mathrm{M} \mathrm{AgNO}_{3}$ solution obtained by mixing $\mathrm{AgNO}_{3}$ with DI water, bare AlSiNT dispersion in DI water obtained by sonication for 3 min, and colloidal AlSiNT/AgNP hybrid solution. A 100 microliter control sample of the diluted bacteria was plated on a trypticase soy agar (TSA) plate to verify the cfu/mL. For each sample, the mixture of bacteria and tested material was centrifuged for $1 \mathrm{~min}$ at $15,000 \mathrm{rpm}$. The cells were resuspended and 100 microliters plated on TSA plates at 0 and $60 \mathrm{~min}$. Plates were incubated $24 \mathrm{~h}$ at 37 degrees $\mathrm{C}$ and the surviving cfu counted.

\section{Results and discussion}

In this work, by utilizing $\mathrm{AgNO}_{3}$ as a silver source, we fabricated AlSiNT/AgNP nanohybrids. The whole process of nanohybrid formation is schematically illustrated in Fig. 2.

The size distribution and morphology of the as-prepared AlSiNT/AgNP nanohybrids were characterized by TEM and STEM. TEM images of the dispersion shown in Fig. 3a, b revealed that the synthesized AgNPs are predominantly spherical in shape. Figure $3 \mathrm{c}$ shows a narrow Ag nanoparticle size distribution measured by TEM with an average size of $3 \mathrm{~nm}$. AlSiNTs remain as closely packed bundles and AgNPs appear to be tethered directly on the bundles of nanotubes. The formation of AgNPs along the nanotube network was further confirmed by energy-dispersive X-ray spectrometer analysis (EDX) given in Fig. 3d, e. The EDX reveals strong signal in the silver region approximately at $3 \mathrm{keV}$. There is also weak $\mathrm{O}, \mathrm{Al}$, and $\mathrm{Si}$ signal in the EDX data, which belongs to AlSiNTs as given in Fig. 3d. Dark-field STEM images shown in Fig. 4 demonstrated that nearly all nanotube surfaces are decorated with a high content of AgNPs, which are evenly spread out on the surface of nanotubes and are well dispersed with no obvious aggregation and coarsening.

To investigate the long-term stability of AgNPs in AlSiNT/AgNP hybrid colloidal solutions, changes in the size distribution of the AgNPs were analyzed using TEM and STEM after a 60-day period and results are given in Fig. 5. Average particle size remained approximately constant with only a very slight growth to $4 \mathrm{~nm}$ in the colloidal solutions that are stored at room temperature as shown by the histogram given in Fig. 5c. Agglomeration was not observed and AgNPs remained anchored on AlSiNT surfaces.

An important finding from these studies is that AlSiNTs are not only inorganic supports to AgNPs, but also present a structurally unique nanotube system in their capability to directly synthesize and immobilize AgNPs preventing the agglomeration effects without the need for reducing and stabilizing agents. To the best of our knowledge, the formation and stabilization of AgNPs could only be achieved through the use of certain reducing and stabilizing agents, and even then obtaining small particles as small as $3 \mathrm{~nm}$ is quite challenging (Bastús et al. 2014; Pinto et al. 2010; Leo et al. 2013). This is the first synthetic route that allows synthesis of highly stable small-sized AgNPs without any chemicals and simultaneous synthesis of novel nanotubebased nanohybrid architectures.

The mechanism by which AlSiNTs results in the formation and immobilization of AgNPs is not fully understood at this time, while further studies are being performed. Nanotubes have a reactive surface that may facilitate the reduction of metal ions leading to the formation of nanoparticles of fairly well-defined dimensions. The effect of AlSiNT presence in the solutions of $\mathrm{AgNO}_{3}$ was studied by UV-Vis spectra and complementary TEM images as shown in Fig. 6. When AlSiNTs were not present, $\mathrm{AgNO}_{3}$ solutions did not result in the formation of AgNPs, and the solution color remained clear with only $\mathrm{UV}-\mathrm{V}$ is wavelength signal coming from the dissolved $\mathrm{Ag}^{+}$ ions at $300 \mathrm{~nm}$. However, when AlSiNTs were added to the 
Fig. 7 Images of TSA plates that were plated with bacteria/ tested solution mixtures at 60 min containing a control of E. coli, b $0.01 \mathrm{M} \mathrm{AgNO}_{3}$ solution, $\mathbf{c}$ AlSiNT solution, and d AlSiNT/AgNP nanohybrid solution
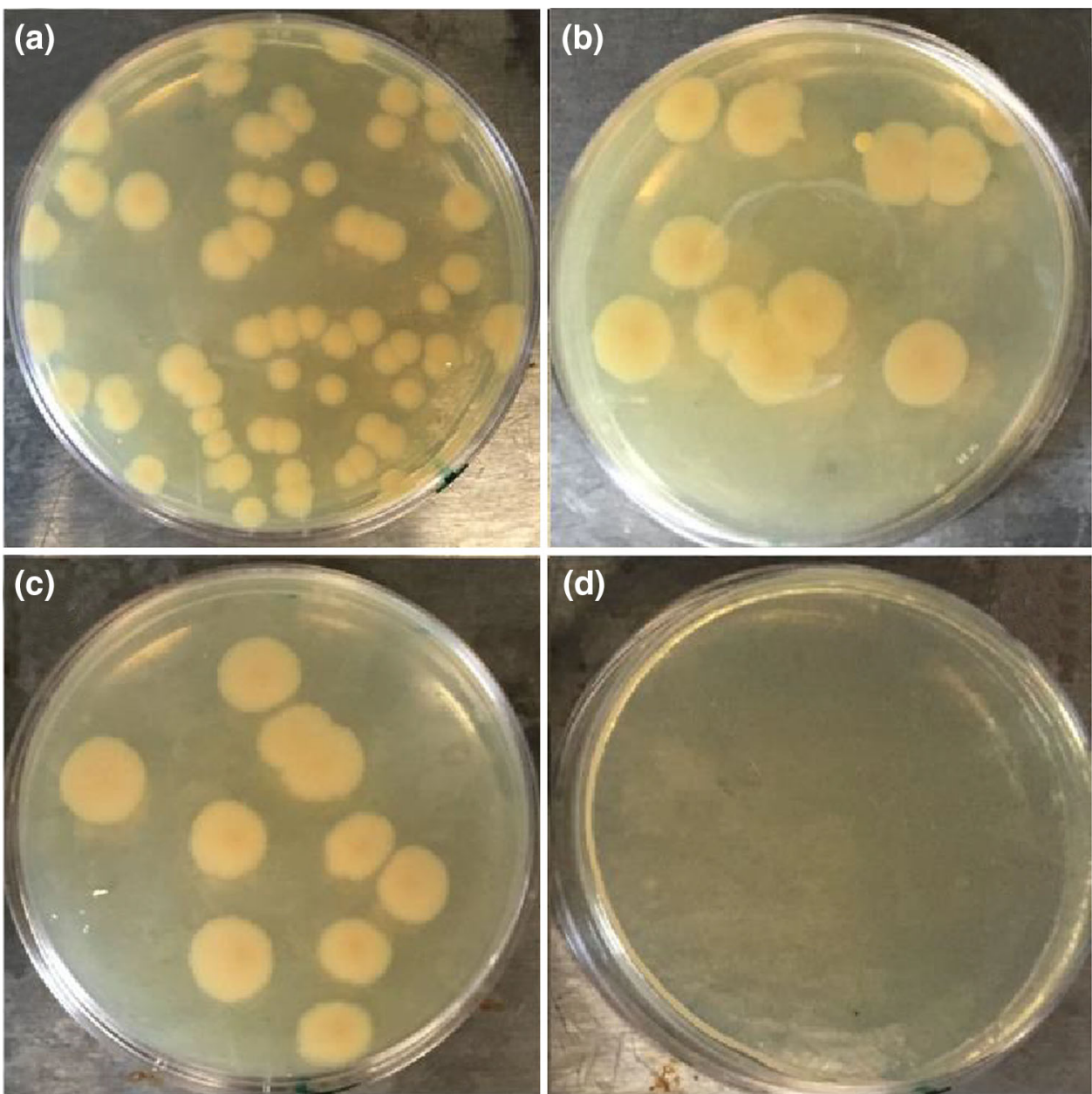
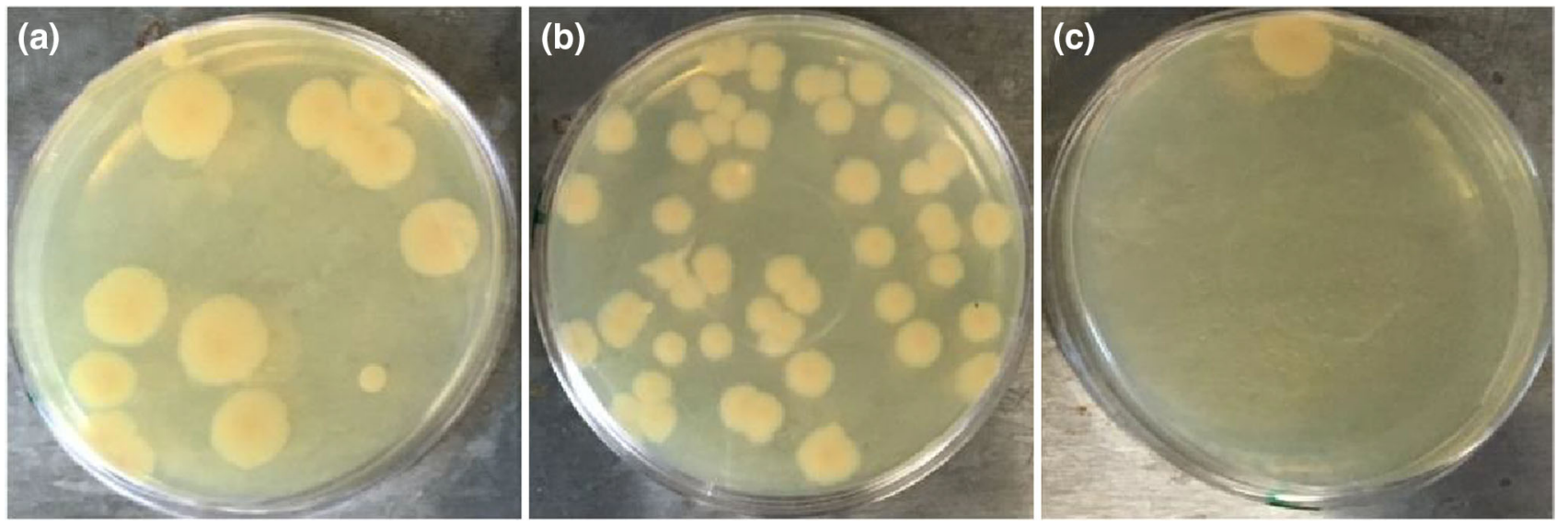

Fig. 8 Images of TSA plates that were plated with bacteria/tested solution mixtures at 0 min containing E. Coli with a $0.01 \mathrm{M} \mathrm{AgNO}_{3}$ solution, b AlSiNT solution, and c AlSiNT/AgNP nanohybrid solution

solutions of $\mathrm{AgNO}_{3}$, nucleation and growth of $\mathrm{Ag}^{0}$ occurred on the surfaces of AlSiNT networks by forming immobilized AgNPs on nanotube surfaces.
The antibacterial activity was examined using E. coli and $S$. epidermidis strains. Initial experiments were conducted to evaluate the antibacterial ability of $\mathrm{Ag}^{+}$and bare 
Fig. 9 Images of TSA plates that were plated with bacteria/ tested solution mixtures at 60 min containing a control $S$. epidermidis, and $\mathbf{b} S$. epidermidis with AlSiNT/AgNP nanohybrid solution
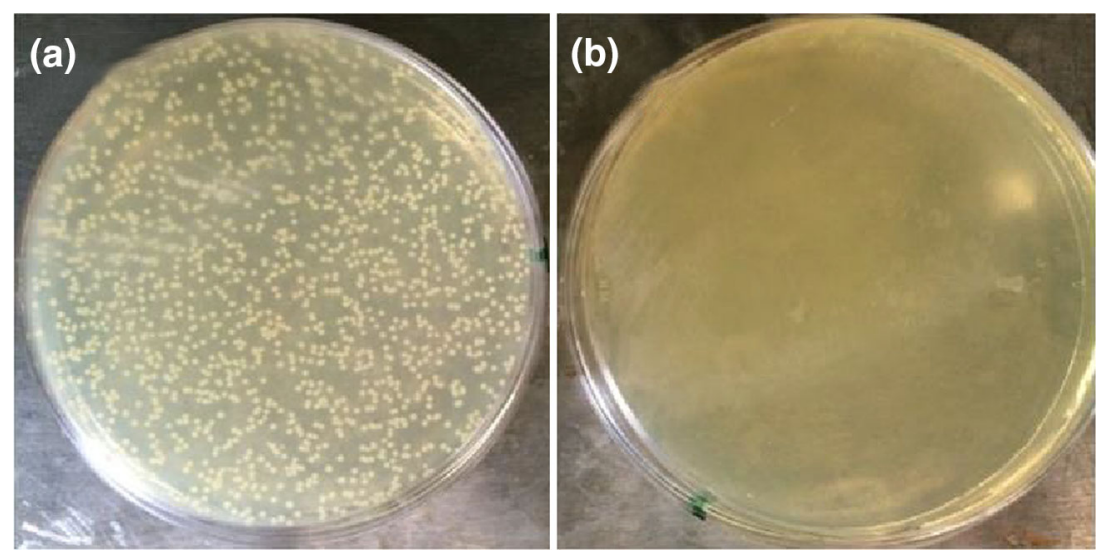

nanotubes against bacteria. As shown in Fig. 7b, c, $\mathrm{AgNO}_{3}$ solution and AlSiNT solution have some antibacterial effect against Gram-negative $E$. coli when compared with control sample (Fig. 7a). These results suggest $\mathrm{Ag}^{+}$ions and nanotubes themselves do not demonstrate strong antibacterial affect against the bacteria. However, when hybrid solutions of nanotubes and Ag nanoparticles were used, no bacterial growth on the plates was observed after 60 min exposure to the hybrid solution as shown in Fig. 7d. More importantly, AlSiNT/AgNP solutions showed an immediate antibacterial effect against $E$. coli when TSA plates were plated at immediately after mixing as shown in Fig. 8c. On the other hand, $\mathrm{Ag}^{+}$ions and bare nanotubes exhibited no significant antibacterial effects at $0 \mathrm{~min}$ of mixing as shown in Fig. 8a, b, respectively. The results observed on Gram-positive $S$. epidermidis strain were similar. As shown in Fig. 9b, no bacterial colonies were formed on plates containing S. epidermidis and AlSiNT/ AgNP nanohybrid solution mixture.

\section{Conclusions}

A novel method has been developed for the synthesis of AlSiNT/AgNP nanohybrids. Small size $(\sim 3 \mathrm{~nm})$ and uniform distribution of AgNPs on AlSiNTs were obtained at room temperature without using reducing/stabilizing agents, any prior surface modification, irradiation, or heat treatment. The other advantages of the method are its simplicity, scalability, and repeatability. An important and exciting implication of the developed method is that peculiar nanotube surface behaves both as a reducing agent and a stabilizer. Nanoparticle morphology/stability can be controlled by surface characteristics of nanotubes and simple aqueous phase chemistry (i.e., by $\mathrm{pH}$ and temperature). The resultant colloidal suspensions can be readily used to prepare nanohybrid films, powders, and gels. Inherent ability of single-walled metal oxide nanotubes to directly form and immobilize metallic agents, without expensive methods and environmentally/biologically toxic substances that hinder their usage, is expected to excite a new field of fundamental research while presenting a unique combination of material systems, which opens up paths for a wide range of applications in nanotechnology from drug delivery to catalysis. Here, we demonstrated that nanohybrids based on AlSiNTs and MNPs show excellent antibacterial activity toward both Gram-positive and Gram negative bacteria and are potential candidate materials to be used in applications where an antibacterial effect is desired.

Acknowledgments This work was supported by Young Investigator Seed Funding through Materials Research Center at Missouri University of Science and Technology.

Open Access This article is distributed under the terms of the Creative Commons Attribution 4.0 International License (http://creativecommons.org/licenses/by/4.0/), which permits unrestricted use, distribution, and reproduction in any medium, provided you give appropriate credit to the original author(s) and the source, provide a link to the Creative Commons license, and indicate if changes were made.

\section{References}

Abid JP, Wark AW, Brevet PF, Girault HH (2002) Preparation of silver nanoparticles in solution from a silver salt by laser irradiation. Chem Commun (7):792-793. doi:10.1039/ B200272H

Anil Kumar S, Abyaneh M, Gosavi SW, Kulkarni S, Pasricha R, Ahmad A, Khan MI (2007) Nitrate reductase-mediated synthesis of silvernanoparticles from $\mathrm{AgNO}_{3}$. Biotechnol Lett 29(3):439-445. doi:10.1007/s10529-006-9256-7

Avellan A, Levard C, Kumar N, Rose J, Olivi L, Thill A, Chaurand P, Borschneck D, Masion A (2014) Structural incorporation of iron into Ge-imogolite nanotubes: a promising step for innovative nanomaterials. RSC Adv 4(91):49827-49830. doi:10.1039/ C4RA08840A

Bastús NG, Merkoçi F, Piella J, Puntes V (2014) Synthesis of highly monodisperse citrate-stabilized silver nanoparticles of up to 200 
nm: kinetic control and catalytic properties. Chem Mater 26(9):2836-2846. doi:10.1021/cm500316k

Boyer M, Paineau E, Bacia-Verloop M, Thill A (2014) Aqueous dispersion state of amphiphilic hybrid aluminosilicate nanotubes. Appl Clay Sci 96:45-49. doi:10.1016/j.clay.2014.04.022

Georgakilas V, Gournis D, Tzitzios V, Pasquato L, Guldi DM, Prato M (2007) Decorating carbon nanotubes with metal or semiconductor nanoparticles. J Mater Chem 17(26):2679-2694. doi:10. 1039/B700857K

Henglein A, Giersig M (1999) Formation of colloidal silver nanoparticles: capping action of citrate. J Phys Chem B 103(44):9533-9539. doi:10.1021/jp9925334

Huang HH, Ni XP, Loy GL, Chew CH, Tan KL, Loh FC, Deng JF, Xu GQ (1996) Photochemical Formation of silver nanoparticles in poly(N-vinylpyrrolidone). Langmuir 12(4):909-912. doi:10. $1021 / 1 \mathrm{a} 950435 \mathrm{~d}$

Ishikawa K, Abe S, Yawaka Y, Suzuki M, Watari F (2010) Osteoblastic cellular responses to aluminosilicate nanotubes, imogolite using Saos-2 and MC3T3-E1 cells. J Ceram Soc Jpn 118(1378):516-520. doi:10.2109/jcersj2.118.516

Jiang Z-J, Liu C-Y, Sun L-W (2005) Catalytic properties of silver nanoparticles supported on silica spheres. J Phys Chem B 109(5):1730-1735. doi:10.1021/jp046032g

Jiravanichanun N, Yamamoto K, Kato K, Kim J, Horiuchi S, Yah W-O, Otsuka H, Takahara A (2011) Preparation and characterization of imogolite/DNA hybrid hydrogels. Biomacromolecules 13(1):276-281. doi:10.1021/bm201616m

Kang D-Y (2012) Single-walled metal oxide nanotubes and nanotube membranes for molecular seperations. Doctoral dissertation

Kang D-Y, Zang J, Wright ER, McCanna AL, Jones CW, Nair S (2010) Dehydration, dehydroxylation, and rehydroxylation of single-walled aluminosilicate nanotubes. ACS Nano 4(8):4897-4907. doi:10.1021/nn101211y

Kang D-Y, Zang J, Jones CW, Nair S (2011a) Single-walled aluminosilicate nanotubes with organic-modified interiors. J Phys Chem C 115(15):7676-7685

Kang D-Y, Jones CW, Nair S (2011b) Modeling molecular transport in composite membranes with tubular fillers. J Membr Sci 381(1-2):50-63. doi:10.1016/j.memsci.2011.07.015

Kang D-Y, Tong HM, Zang J, Choudhury RP, Sholl DS, Beckham HW, Jones CW, Nair S (2012) Single-walled aluminosilicate nanotube/poly (vinyl alcohol) nanocomposite membranes. ACS Appl Mater Interfaces 4(2):965-976

Kong B-S, Jung D-H, Oh S-K, Han C-S, Jung H-T (2007) Singlewalled carbon nanotube gold nanohybrids: application in highly effective transparent and conductive films. J Phys Chem C 111(23):8377-8382. doi:10.1021/jp071297r

Krklješ AN, Marinović-Cincović MT, Kacarevic-Popovic ZM, Nedeljković JM (2007) Radiolytic synthesis and characterization of Ag-PVA nanocomposites. Eur Polymer J 43(6):2171-2176. doi:10.1016/j.eurpolymj.2007.03.023

Kuroda Y, Fukumoto K, Kuroda K (2012) Uniform and high dispersion of gold nanoparticles on imogolite nanotubes and assembly into morphologically controlled materials. Appl Clay Sci 55:10-17. doi:10.1016/j.clay.2011.07.004

Lee K-S, El-Sayed MA (2006) Gold and silver nanoparticles in sensing and imaging: sensitivity of plasmon response to size, shape, and metal composition. J Phys Chem B 110(39):19220-19225. doi:10.1021/jp062536y

Leo BF, Chen S, Kyo Y, Herpoldt K-L, Terrill NJ, Dunlop IE, McPhail DS, Shaffer MS, Schwander S, Gow A, Zhang J, Chung KF, Tetley TD, Porter AE, Ryan MP (2013) The stability of silver nanoparticles in a model of pulmonary surfactant. Environ Sci Technol 47(19):11232-11240. doi:10.1021/es403377p

Levard C, Rose J, Thill A, Masion A, Doelsch E, Maillet P, Spalla O, Olivi L, Cognigni A, Ziarelli F, Bottero JY (2010) Formation and growth mechanisms of imogolite-like aluminogermanate nanotubes. Chem Mater 22(8):2466-2473. doi:10.1021/cm902883p

Li X, Jia Y, Cao A (2009) Tailored single-walled carbon nanotube-CdS nanoparticle hybrids for tunable optoelectronic devices. ACS Nano 4(1):506-512. doi:10.1021/nn901757s

Mackiewicz N, Surendran G, Remita H, Keita B, Zhang G, Nadjo L, Hagège A, Doris E, Mioskowski C (2008) Supramolecular selfassembly of amphiphiles on carbon nanotubes: a versatile strategy for the construction of CNT/metal nanohybrids, application to electrocatalysis. J Am Chem Soc 130(26):8110-8111. doi: $10.1021 / j a 8026373$

Moritz M, Geszke-Moritz M (2013) The newest achievements in synthesis, immobilization and practical applications of antibacterial nanoparticles. Chem Eng J 228:596-613. doi:10.1016/j.cej. 2013.05.046

Navaladian S, Viswanathan B, Viswanath RP, Varadarajan TK (2007) Thermal decomposition as route for silver nanoparticles. Nanoscale Res Lett 2(1):44-48. doi:10.1007/s11671-006-9028-2

Pinto VV, Ferreira MJ, Silva R, Santos HA, Silva F, Pereira CM (2010) Long time effect on the stability of silver nanoparticles in aqueous medium: effect of the synthesis and storage conditions. Colloids Surf A 364(1-3):19-25. doi:10.1016/j.colsurfa.2010.04. 015

Pol VG, Grisaru H, Gedanken A (2005) Coating noble metal nanocrystals $(\mathrm{Ag}, \mathrm{Au}, \mathrm{Pd}$, and $\mathrm{Pt})$ on polystyrene spheres via ultrasound irradiation. Langmuir 21(8):3635-3640. doi:10.1021/ la047465d

Rai M, Yadav A, Gade A (2009) Silver nanoparticles as a new generation of antimicrobials. Biotechnol Adv 27(1):76-83. doi:10.1016/j.biotechadv.2008.09.002

Sondi I, Goia DV, Matijević E (2003) Preparation of highly concentrated stable dispersions of uniform silver nanoparticles. J Colloid Interface Sci 260(1):75-81. doi:10.1016/S00219797(02)00205-9

Sun Y, Xia Y (2002) Shape-controlled synthesis of gold and silver nanoparticles. Science 298(5601):2176-2179. doi:10.1126/ science. 1077229

Thill A, Maillet P, Guiose B, Spalla O, Belloni L, Chaurand P, Auffan M, Olivi L, Rose J (2012) Physico-chemical control over the single- or double-wall structure of aluminogermanate imogolitelike nanotubes. J Am Chem Soc 134(8):3780-3786. doi:10.1021/ ja209756j

Wu B, Kuang Y, Zhang X, Chen J (2011) Noble metal nanoparticles/carbon nanotubes nanohybrids: synthesis and applications. Nano Today 6(1):75-90. doi:10.1016/j.nantod.2010.12.008

Yin H, Yamamoto T, Wada Y, Yanagida S (2004) Large-scale and size-controlled synthesis of silver nanoparticles under microwave irradiation. Mater Chem Phys 83(1):66-70. doi:10.1016/j. matchemphys.2003.09.006

Yucelen GI, Choudhury RP, Vyalikh A, Scheler U, Beckham HW, Nair S (2011) Formation of Single-walled aluminosilicate nanotubes from molecular precursors and curved nanoscale intermediates. J Am Chem Soc 133(14):5397-5412. doi:10. $1021 / j a 111055 \mathrm{q}$

Yucelen GI, Kang D-Y, Guerrero-Ferreira RC, Wright ER, Beckham HW, Nair S (2012) Shaping single-walled metal oxide nanotubes from precursors of controlled curvature. Nano Lett 12(2):827-832 